\title{
A RIPPLE EFFECT OF COVID-19 PANDEMIC ON SHORTAGE OF MEDICINAL PRODUCTS AND ITS IMPACT ON PATIENT CARE
}

\author{
BIPLAB KUMAR DEY ${ }^{1}$, EFFICIENCY MYRSING ${ }^{1}$, RUHUL AMIN ${ }^{*}$, FARUK ALAMํㅜ, MD. MIZANUR RAHMAN², PAL \\ GOGOI ${ }^{1}$, TAHMINA AFROZ ${ }^{2}$
}

\author{
${ }^{1}$ Faculty of Pharmaceutical Science, Assam Down Town University, Panikhaiti, Guwahati, Assam, India, ${ }^{2}$ Pharmacy Department, Daffodil \\ International University, Dhaka, Bangladesh, India \\ Email: ruhulglp18@gmail.com
}

Received: 25 May 2021, Revised and Accepted: 28 Jul 2021

\section{ABSTRACT}

Objective: Shortages of medicinal products are complex global problems. Drug shortages remain a significant public health issue. Global shortages of medical products have a potential effect on patient health and total healthcare costs. Countries worldwide, especially those affected by Coronavirus disease 2019 (COVID-19), is experiencing a rapid increase in drug shortage, which causes several complications for physicians, health care provider, patients, health institutes and health regulatory bodies.

Methods: To carry out the study of shortages, several efforts have been taken by the regulators and industries. Prominent amongst these include FDA's research the needs and the reforms made in the regulations about shortages. We also searched for electronic databases (PubMed, Science direct, Web of Science) using the terms (COVID-19 and shortage) or (medicine and COVID-19) for articles in periods of 2019 to 2021.

Results: On assessment based on the report, the number of shortage drugs in 2020 is 835; Anesthesia drugs are highest during the COVID-19 outbreak data indicate the number of shortages is 143 in USA. It was found that generic products were mostly in short supply, with antimicrobial agents (63\%) topping the list of therapeutic categories of medicines with interrupted supply, followed by oncology medicines (47\%) and then anesthetic agents (38\%) during COVID-19 pandemic.

Conclusion: Many steps have been taken to reduce the impact of a shortage of health care. Agencies like the United States Food and Drug Administration (US FDA) and European Medicines Agency (EMA) has established guidelines and works with manufacturers and other partners to help prevent shortages. This article aims to the analysis the root cause of medicinal product shortages, their effects on the patient outcome, medication error, which occurs due to the substitution safe and effective therapies with alternative treatments, identify possible solutions and policies established to manage medicinal product shortages.

Keywords: Drug shortage, Unavailability, COVID-19, US FDA, EAHP, Medicinal product shortage

(C) 2021 The Authors. Published by Innovare Academic Sciences Pvt Ltd. This is an open access article under the CC BY license (https://creativecommons.org/licenses/by/4.0/] DOI: https://dx.doi.org/10.22159/ijap.2021v13i5.42177. Journal homepage: https://innovareacademics.in/journals/index.php/ijap

\section{INTRODUCTION}

In this modern world, medication shortages are not expected to be a huge issue, where the supply issue of medication is quickly resolved without harmful effects on the quality of patient health and life due to the improvement of manufacturing, distribution, and transportation. But unfortunately, the Medication shortage is described as a growing issue all over the world.

According to the US FDA, medication shortages are defined as a "period when the command or projected demand for the drug is more than the supply of the drug" [1-4]. The American Society of Health-System Pharmacists (ASHP) defines shortage as "A supply issue that affects how pharmacies formulate and distribute a drugs or that impacts patient care when prescribers necessary to find an alternative treatment because of supply issues" [5].

Drug shortages have grate impact on patient health by causing substitution of safe and effective therapies with less effective or less tolerant alternative treatments, compromising or delaying medical procedures, or causing medication errors $[6,7]$. These outcomes can lead to prolonged patient suffering, disease progression, and hostile health outcomes that reduce patient well-being [4]. Based on The survey report of U. S. community hospitals, $56 \%$ of hospitals reported they had changed patient care or delayed therapy during $\mathrm{F}$. Y. 2015-2017 because of drug shortages; $36.6 \%$ said they had rescheduled non-urgent or emergent procedures [8].

Shortage of normal saline in the USA since 2014 (especially during the outbreaks of influenza cases in 2018) occurs due to increasing demand and the dependence of the supply on just a few manufacturers. Roughly one million units of normal saline and almost half of all normal saline in the United States were manufactured and Baxter ships. WheBaxter's manufacture in Puerto Rico was being stopped due to Hurricane Maria, a national reserve of normal saline was being depleted, and there was no sustainable solution to this fragile supply chain [9].

Drugs likely to shortage are norepinephrine, sterile injectable medications because of their short shelf life. As norepinephrine is the initial choice vasopressor for the treatment of hypotension due to septic shock, therefore, shortage in norepinephrine would significantly increase mortality in patients with septic shock [10]. Other examples of drug shortages during 2016 and 2017 include multiple intravenous antibiotics (aminoglycosides, ciprofloxacin, extended-spectrum penicillin's, third-generation cephalosporin's, and vancomycin), inotropes and vasopressors (dobutamine and dopamine), chemotherapy agents (bleomycin, cisplatin, doxorubicin, etoposide, and methotrexate), and various drugs used in the intensive care unit, such as calcium, sodium bicarbonate, shortacting muscle relaxants, fentanyl, and morphine [11].

Countries worldwide, especially those affected by this present pandemic (COVID-19), are experiencing a rapid increase in drug shortage, which causes various troubles for doctors, health care providers, patients, and national regulatory bodies [12, 13]. One of the significant reasons for medicinal product shortage during this pandemic is Restricting international commercial and trading channels to reduce the spread of COVID-19 [14,15]. The outbreak of the COVID-19 pandemic globally causes an unprecedented demand for medical resources, particularly Personal Protective Equipment (PPE) and ventilators [16]. This has impacted to shortages in various countries, with some limiting their use of PPE and, in some cases reusing disposable material [17]. The consequence of this is increasing at the rate of contagion between health care 
professionals, which contributes to spreading disease. This may be because of a local lack of PPE but relatively than a national shortage resulting from the improper distribution of resources $[18,19]$.

To understand the situation and provide industries and other stakeholders of the healthcare e system to handle such Changes to the laws and regulations to ensure effective communication between industries, key persons in the supply chain, and the concerned authorities. One such reform is an amendment of the Federal Food Drugs and Cosmetics Act (FFDandC Act) by updating section 506C [11]; section 506C sets out the requirement that manufacturers inform the U. S. Food and Drug Administration (FDA or the Agency) of a permanent discontinuance or interruption in the manufacture of any prescription and life-saving drug, life-sustaining drug, or drug proposed for use in the prevention or treatment of a debilitating disease or condition $[4,20]$. This amendment was a response to the presentation of FDASIA (Food and Drug Administration Safety and Innovation Act).

Setting FDA's (Food and Drugs Administration) way of responding to the shortage situation as an example, the European Union and other countries worldwide started tackling drug shortages by conducting surveys and analyses of the therapeutic areas affected. European Association of Hospital Pharmacists (EAHP) conducted such surveys to analyze the situation at a Europe-wide level and bridge the gap of information, which existed between what, was communicated and what happened concerning drug shortage situations [21].

Similarly, in India, in 2015, NPPA (National Pharmaceutical Pricing Authority) created a web-enabled system called Pharma Jan Samadhan [22]. The scheme provides consumers with an online platform where they can report their complaints related to overpricing of medicines, unavailability of drugs, and withhold supplies for sale of any drug without a valid reason. With this scheme, information regarding shortages is easily communicated to NPPA.

\section{Causes of drug shortages}

There are many reasons for drug shortages. Some of the main reasons are Manufacturing Difficulties, Natural Disasters, Supply and Demand Issues, Business and Economic Issues, needs of Raw Materials, Regulatory Issues, Supply Chain Issues, and Health Care System Practices [4] (fig. 1).

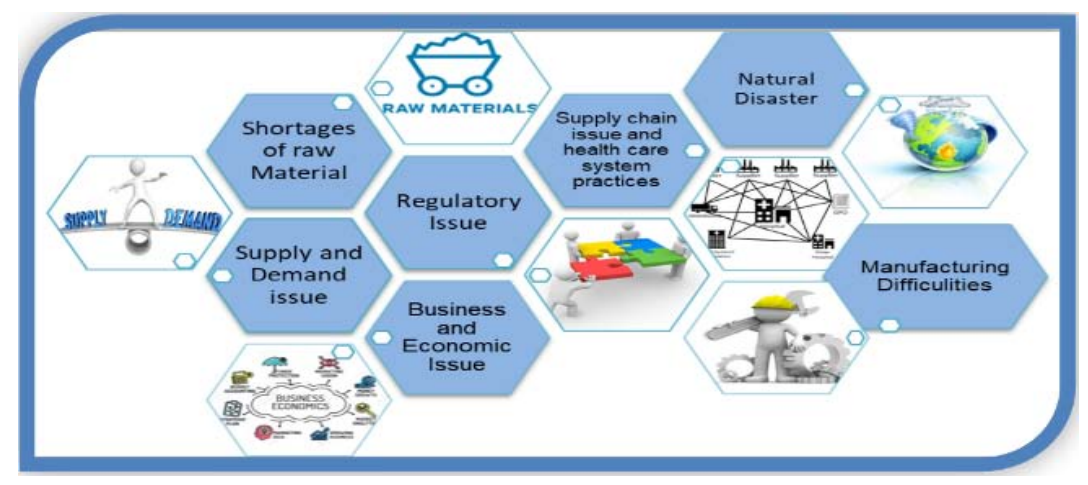

Fig. 1: Depict some common causes of the medicinal product shortage (4)

Drug shortage program, as of March 2019 to April 2020, Manufacturing problem(66\%), demand increase (17\%), shipping delay(11\%), ingredient shortage(2\%), manufacturing practices
(1\%). where the most common known causes of shortages. However, the other $3 \%$ of drug shortages were classified as an "unknown" cause [23, 24] (fig. 2).

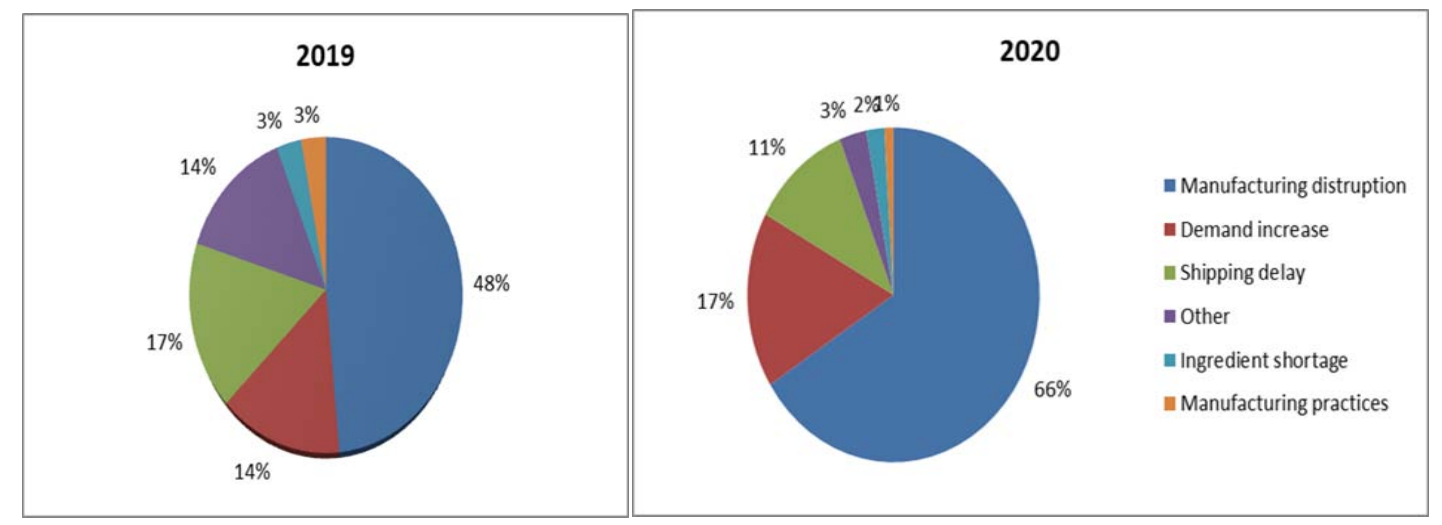

Fig. 2: Depict the impact of COVID-19 on drug shortages $(18,19)$

\section{MATERIALS AND METHODS}

To carry out the study of shortages, several efforts have been taken by the regulators and industries. Prominent amongst these include FDA's research the needs and the reforms made in the regulations about shortages. We also searched for electronic databases (PubMed, Science direct, Web of Science) using the terms (Covid-19 and shortage) OR (medicine and Covid-19) for articles in periods of 2019 to 2021.

\section{Data source}

Section 506C-1 of FFDCA (Federal Food Drugs and Cosmetics Act) mandates FDA to send an annual report to Congress on drug shortages [4]. Accordingly, details related to medicine shortages observed each year are reported to Congress and are made available in the public domain. Outcomes of FDA's measures in documenting and responding to shortages prompted the European health sector to survey drug shortages EAHP's drug shortages survey 2014 [25] 
was published. The latest survey conducted by EAHP has been published EAHP's 2019 [21] Survey on drug shortages in the hospital sector-prevalence, nature, and impact on patient care.

The International Society for Pharmaceutical Engineering (ISPE), an interested party in the global pharmaceutical industry, was convinced about the necessity of having a close collaboration and intense dialogue between the pharmaceutical industry and international health authorities to address drug shortages [16]. Hence ISPE tried to address the problem at a technical level. Thus, a drug shortages task force was formed in late 2012 to help stakeholders understand the root causes of global shortages [16]. Their work was published in the"Report on ISPE drug shortages survey" in 2013.

In addition to these reports, several articles about drug shortages that discuss the consequences of some major shortages have been referred.

\section{UFDA survey}

The Food and Drug Administration (FDA) is a regulatory agency under the U. S. Department of Health and Human Services. FDA primary responsibilities are to protect the health of the public by promising that foods (excluding livestock, poultry meat products which the U. S. Department of Agriculture regulates) are safe and properly labelled; ensuring that human, veterinary medicines, vaccines, medical devices and other biological products proposed for human usage are effective and safe; Protecting the public from various radiation generate from electronic device; Assuring herbal, cosmetics and nutraceutical supplements are nontoxic and properly labelled; Regulating narcotics products; Evolving the public health awareness by helping to accelerate product innovations [26].

\section{EAHP survey}

The European Association of Hospital Pharmacists (EAHP) was founded in 1972 as a federation of hospital pharmacists' national associations. It represents more than 23,000 hospital pharmacists in 35 European countries. The first member countries, which include EAHP, were Belgium, Denmark, Britain, France, the Federal Republic of Germany, and The Netherlands. In 1973, Spain and Ireland merged EAHP, soon followed by Austria, Norway, Greece, Sweden, and Switzerland. In the 1990s, Italy, Hungary, Portugal, Slovakia, Luxembourg, Finland, Croatia, Slovenia, and the Czech Republic became members. Lithuania, Estonia, Latvia, Serbia, Poland, North Macedonia, Turkey, Herzegovina, Bulgaria, and Bosnia followed. More recently, Malta, Iceland, Montenegro and Romania became associated with EAHP. EAHP supports the profession through science and networking with sister associations as well as stakeholders in European projects on patient safety, education, and procurement [27].

Key considerations of the survey include affected medicines, impact on health care, actions taken to reduce the effect on healthcare, duration of shortages, and supply of medicines.

\section{ISPE survey}

Drug Shortage Survey of ISPE, which was conducted from Feb-March 2013, emphasizes understanding and identifying the technical and GMP non-compliance-related issues that cause the drug shortages, facing by the pharmaceutical industry. The main aim of this survey is to recognize the core cause of manufacturing or quality-related and provide guidelines to industry and regulators to avoid or alleviate drug shortages.

\section{Overall, the task force expected the results of this $s$}

tudy would provide ISPE with unique industry data regarding drug shortages. Through this report and subsequent activities, ISPE plans to offer the pharmaceutical industry and health authorities' muchneeded data to support additional discussion and the development of science and risk-based approaches to mitigate shortages. Around 175 subjects and 37 industries from across the world participated in the survey. This fetched 212 total respondents providing data concerning an actual drug shortage or a near miss. With the help of this study, ISPE planned to develop a knowledge and risk-based approach to alleviate shortages [28].

\section{RESULTS}

\section{US FDA analyses}

The following fig. depicts the number of new drug shortages identified by the FDA from 2010 to December 31 st, 2019 (fig. 3).

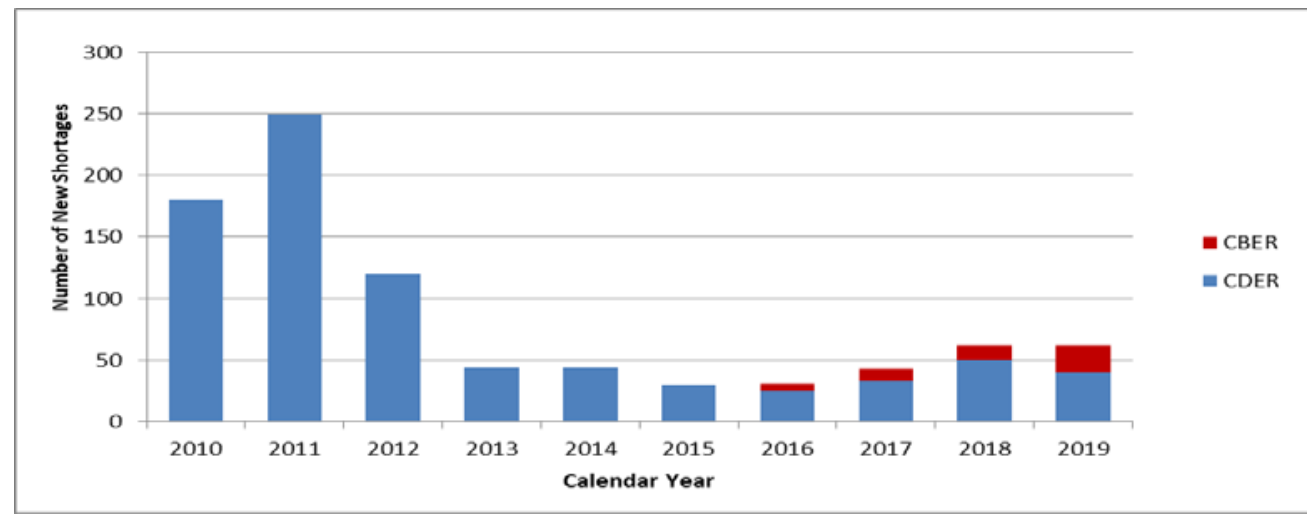

Fig. 3: Trend of occurrence of new drug shortage 2010 to 2019

Although the bar graph shows a decline in the number of new drug shortages since 2011, the fact that shortages still pose a threat to health care should not be overlooked. The incidents of shortages involving drug use in cancer treatment, drugs to provide parenteral nutrition, such shortages lead to the alternative prescription therapies, which could be less potent or presents additional adverse effects. The calendar Year 2019 has been a challenging year for shortages, even though there has been a steady decrease in new shortages for the last few years. The FDA observed the effects from the closing of two facilities by major drug manufacturers for remediation purposes in 2017 and 2018, leading to the loss of manufacturing capacity needed for the supplies of various drug products [4].
As per USFDA report 2021, the drug shortage was categorized therapeutics and yearly wish. An assessment based on the report, we found the highest need for drugs during the COVID-19 Era. The number of shortage drugs in 2020 is 835 , in the various therapeutic area contributing to maximum lack of drugs due to different manufacturing, availability of raw materials, and shipment related issues during the COVID-19 outbreak. The preCOVID-19 has a drug shortage due to discontinued drug or regulatory issues, but it can manage later on. The therapeutics shortages of anesthesia drugs are highest during the COVID-19 outbreak in 2020; data indicate the number of shortages is 143 . We can establish COVID-19 outbreak from the above data dramatically increased the drug shortage (fig. 4) [29]. 


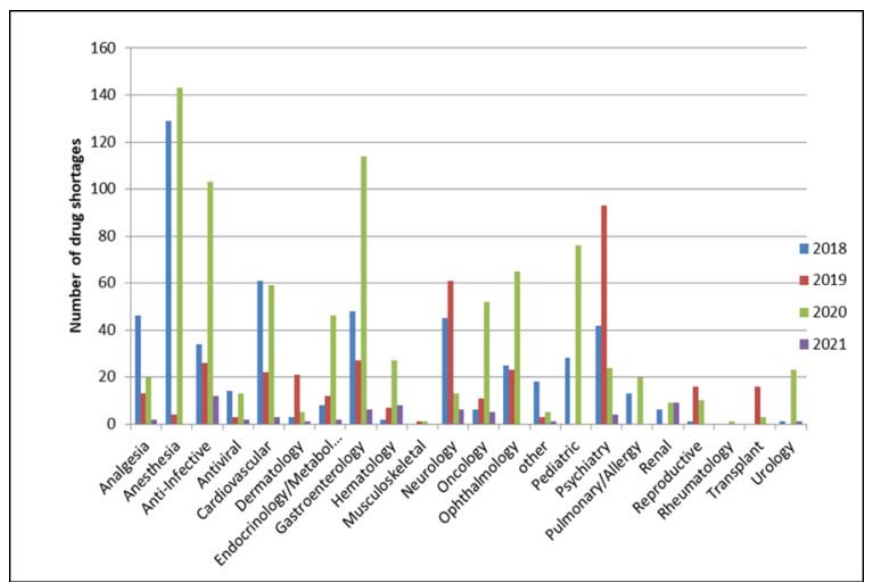

Fig. 4: Depict the amount of a drug shortage as per USFDA recent update $(4,24)$

\section{EAHP survey}

Medicines Shortages Survey done by the European Association of Hospital Pharmacists (EAHP) in 2019 explored issues linked to communications of medicines shortages within hospitals and other possible reasons of shortages and their impact on patients' care. In addition, they collected current management strategies by performing queries on how survey participants would like to see medicines shortages handled and/or resolved [30].

EAHP Medicines Shortages Survey in 2014 and 2018 collected information on the impact medicines shortages have on patients and hospital pharmacists [30, 31]. However, for the 2019 edition of EAHP's Medicines Shortages Survey, the decision was taken to expand the survey to physicians, nurses, and other healthcare professionals working in the hospital environment. Also, patients were promoted to provide feedback on their experiences with medicines shortages. Data from these groups were collected between November $7^{\text {th }}, 2019$, and January $13^{\text {th }}, 2020$. The survey questions were made available via Survey Monkey in Bosnian/Croatian, English, French, Greek, Italian, Portuguese, Romanian, Serbian, Slovak, and Spanish. And it aimed to detect statistically significant differences in the number of respondents in a country reporting shortages to be a problem in giving the best care to patients and operating the hospital pharma' between 2018 and 2019 surveys were performed [21].

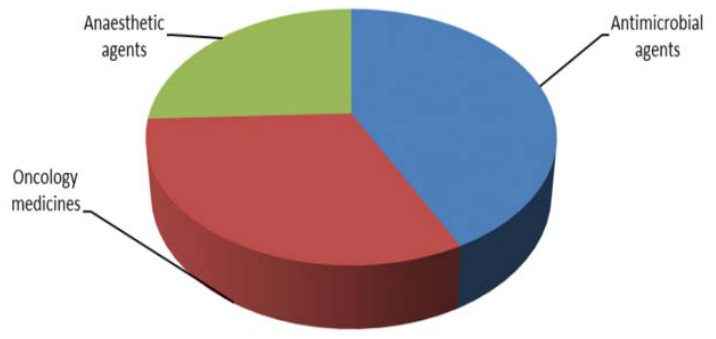

Fig. 5: Depict the type of medicines most frequently in shortage (25)

Through this study, it was found that generic products were mostly in short supply, with antimicrobial agents (63\%) topping the list of therapeutic categories of medicines with interrupted supply, followed by oncology medicines $(47 \%)$ and then anesthetic agents (38\%) were named by hospital pharmacists as top three medicines frequently in shortage in 2019 (fig. 5).

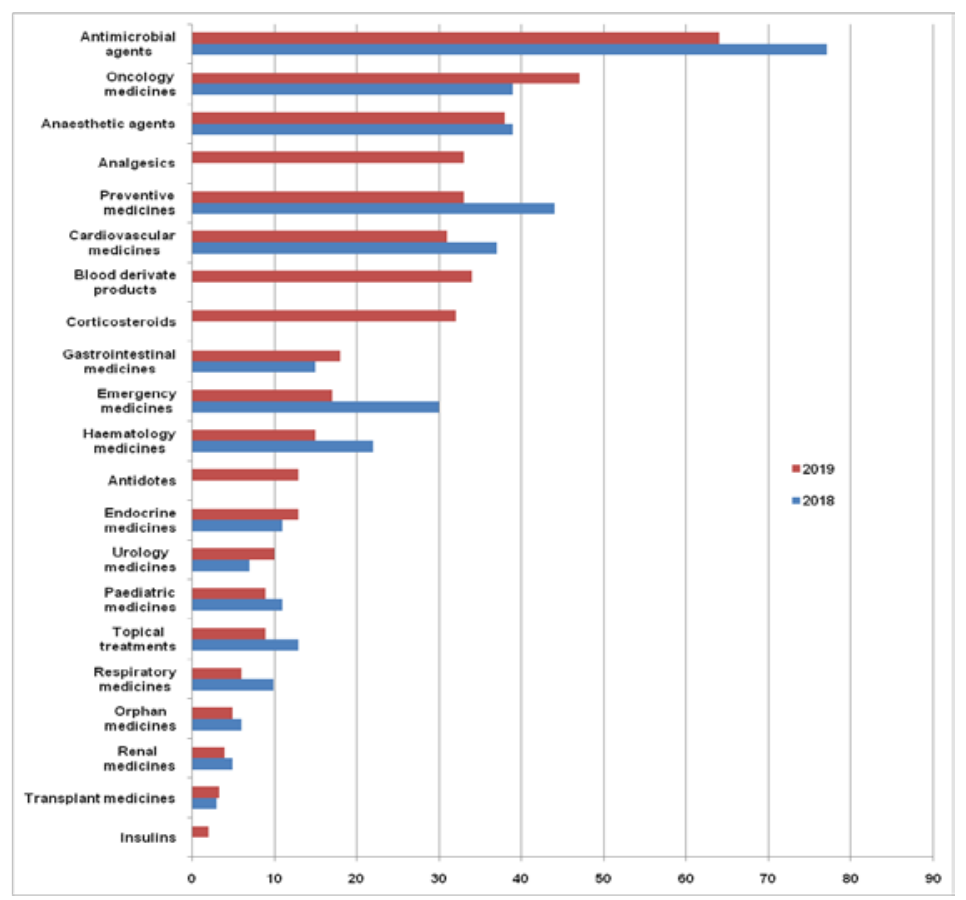

Fig. 6: Shows the comparison of 2018 and 2019 medicines shortage according to EAHP 2019 report (25) 
They represent the Comparison of Medicines Shortages Survey report conducted between 2018 and 2019; shortages of oncology medicines increased from $39 \%$ in 2018 to $47 \%$ in 2019 , while those anesthetic agents remained stable with $39 \%$ in 2018 and $38 \%$ in 2019. After the increase to $77 \%$ in 2018 from $57 \%$ in 2014, the reports of antimicrobial agents decreased to $63 \%$ (fig. 6).

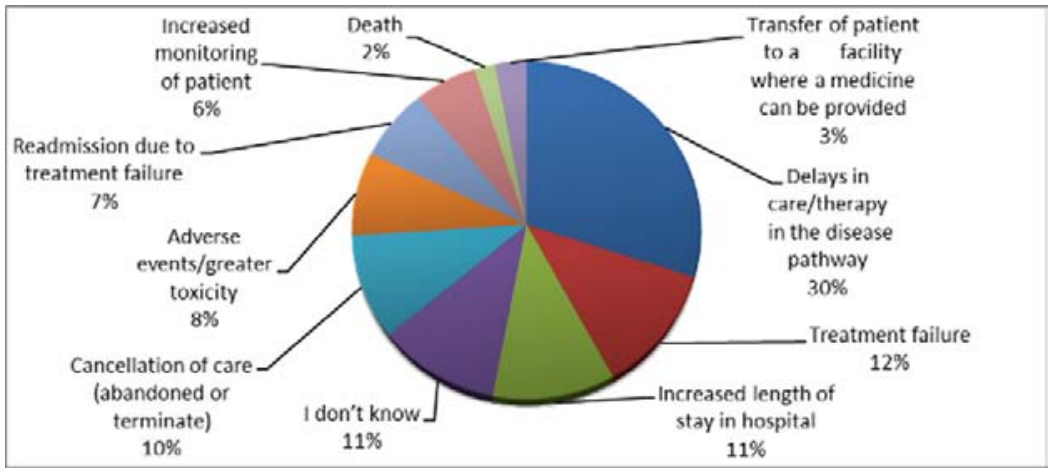

Fig. 7: Shows the type of impact medicine shortages had on patient care as per the 2019 edition of EAHP's Medicines Shortages survey (25)

The impact is resulting from medicines shortages on the patients, which highlights the magnitude of this problem. 30\% of the respondents responded to care delayed due to medicine shortages, $12 \%$ experienced a failure of treatment, and $11 \%$ had an increased length of stay in the hospital. $10 \%$ of the patients had their treatment canceled, while $8 \%$ experienced adverse events or more significant toxicity. Readmission due to treatment failure $7 \%$ and increased monitoring were presented by $6 \%$ of the population; in addition, $3 \%$ (of the patients were transferred to a facility where a pharmacist could provide the medicine. $2 \%$ of respondents answered that they knew of instances where the death had occurred due to medicines shortages. $11 \%$ stated that they didn't know what type of impact the medicine shortage had on their treatment (fig. 7).

\section{ISPE survey}

International Society for Pharmaceutical Engineering (ISPE) addresses the complex medicine shortage problem and the requirement of collaboration and clear communication between the pharmaceutical industry and global health authorities. In response to this problem, ISPE has aimed to discover whether the manufacturing or quality-related root causes or mitigations could be identified that could help industries and regulators to avoid medicines shortages [28].

\section{Following are specific objectives of the ISPE survey}

1. Recognition and collect views from companies and individuals on a global basis and evaluate the result from both a technical perspective and an organizational perspective.

2. To Confirm and determine the source of shortages in support of developing a risk-based approach to reduce shortages.

3. To differentiate between companies that had fully developed in preventing and avoiding medicine shortage with those who had experienced an actual shortage.

4. To identify any distinctions between non-sterile and sterile products.

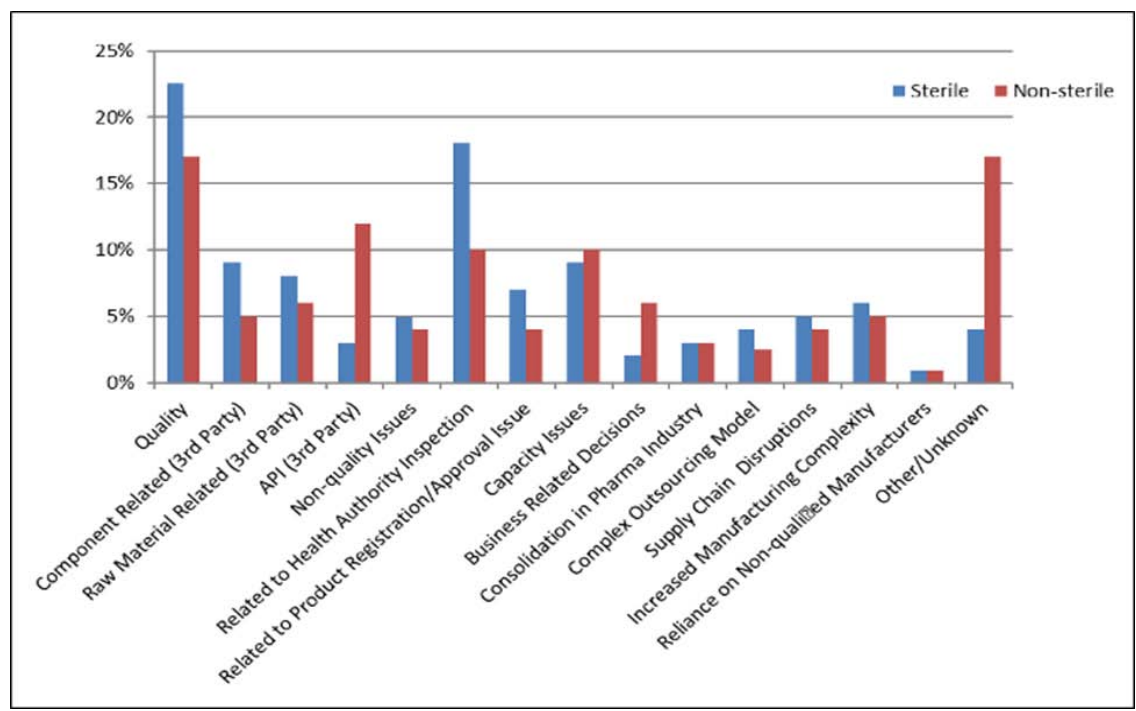

Fig. 8: Factors contributing to drug shortage as per ISPE 2013 drug shortage survey (23)

As per the 2013 ISPE drug shortage report [28], in the case of sterile products, we found that quality-related issues contribute to most of the drug shortage $(23 \%)$, followed by health Authority inspectionrelated problems $(18 \%)$. Both components-related ( $3^{\text {rd }}$ party) and capacity issues contribute $9 \%$ of drug shortage. Whereas business- related decisions, Reliance on Non-qualified manufacturer is the least factors, i.e., contributing $2 \%, 1 \%$ of the drug shortage, respectively. But in the case of non-sterile products, both Quality and other/unknown related issues contribute $17 \%$ of a drug shortage, followed by API-related issues (12\%), and again, Reliance on Non- 
qualified manufacturers are the least factor contributing only $1 \%$ of non-sterile product shortage (fig. 8).

\section{DISCUSSION}

The studies give us an understanding of the grave impact shortages have on health care. Drug shortages may occur due to noncompliance with current GMP and are forced to halt production, closing of API (Active Pharmaceutical Ingredient) plant, or destroying API plants due to natural calamities unavailability of that API which in turn caused shortages of products made with that API. Sometimes, unspecified degradants in raw materials beyond acceptable limits lead to holding the materials creating its shortage.

The devastated effect of Hurricane Maria on the manufacturing plants in Puerto Rico of sterile saline in 2017 had a major impact on drug manufacturing because Puerto Rico is home to the main manufacturing plant for small-volume normal saline Made by Baxter $[32,33]$. There is a variety of other reason for drug supply shortages, some of which government agencies and other stakeholders can solve it, including, pharmaceutical manufacturers, wholesalers, purchasing agencies, medical insurance plans, regulators and the pharmacy profession to identify these issues and works to ensure a continuous supply of drug so that the appropriate treatment can be given to patients. In addition, manufacturing quality problems implicate shortages of products produced by a limited number of distributors, such as propofol, imiglucerase, agalsidase $\beta$, and influenza vaccine [34].

The global drug supply has been severely impacting by the COVID19 outbreak, and the consequences of this shortage could be harmful. They may last for an extended period, primarily due to the global economy's disruption [14]. About $67 \%$ and 345 billion units of Medical gloves were supplied by Malaysia's industry annually, but because COVID-19 lockdown in Malaysia leads to a Medical gloves shortage [35].

Drug shortages have forced the pharmacist and other health professionals to use alternative therapy. Alternative drugs may be less effective and may cause a high risk of developing unwanted effects and may increase the risk of a drug overdose because of changes in drug strength and formulation. Patient care has to be compromised [14]. Drug shortages have a severe impact on the most vulnerable patients. According to the USFDA report, it was estimated that $90 \%$ of the 3,000 children who have T-cell acute lymphoblastic leukemia (ALL) are curable. However, many of the drugs used to treat children with ALL are older drugs, hence making them more vulnerable to the shortage. From 2009-2019, 9 out of 11 drugs used for ALL were in and out of shortage. In addition, according to The American Association of Nurse Anaesthetists reports, Lidocaine shortage has resulted in a patient who receives propofol feeling a burn on induction, leading to agitation at precisely the time a patient should be relaxed and without stress as they undergo sedation or anesthesia. Decisions regarding alternative agents should be made in collaboration with all health professionals like medical, nursing, and pharmacy representatives, and it should get approved by the appropriate medical committees. After making a decision, the therapeutic alternative should ensure an adequate supply. The health care facility should also be prepared if a shortage and an appropriate alternative agent should be subsequently developed [5].

The collaborative approach is necessary for sustainable solutions to the medicine shortage problem; several stakeholder groups have also issued guidance documents to assist in prevention and mitigation strategies. Additionally, several groups were instrumental in facilitating conversations surrounding the issue as well as advocating for legislative and regulatory changes that made it possible for many of the current strategies to be implemented. These organizations have included the American Medical Association, American College of Cardiology, American Hospital Association, ASCO, and ASHP [36].

Since 2010, many amendments made to the laws and regulations about the supply of drugs. The provisions required all applicants and manufacturers of drugs and biological products to notify the FDA through online submission about a permanent discontinuance or an interruption in manufacturing the product, which can cause significant disturbance in the product's supply. This decreased drug shortages in the subsequent years by many folds because the FDA started helping pharmaceutical companies solve compliance issues. They also searched for alternative producers and collaborated with them to make sure they can increase production to meet demands.

\section{CONCLUSION}

Medication shortages require significant attention from multistakeholder, regulators, industrialists, policy-makers, and healthcare providers. This study also indicated the medicine shortage is increased in a pandemic situation. The research paper gives us a clear understanding that regulatory agencies, industries, and hospital pharmacies must implement some of the identified drug shortage management strategies. A collaboration of all stakeholders in the management of shortages is also essential to addressing medicine shortages. Educating healthcare professionals, students, and patients about drug shortages is also essential.

\section{ABBREVIATION}

1. API: Active Pharmaceutical Ingredient

2. ASHP: American Society of Health-System Pharmacists

3. ASCO: The American Society of Clinical Oncology

4. EAHP: European Association of Hospital Pharmacists

5. ISPE: International Society for Pharmaceutical Engineering

6. FDA: The Food and Drug Administration

7. FFDCA: Federal Food Drugs and Cosmetics Act

\section{FUNDING}

Nil

\section{AUTHORS CONTRIBUTIONS}

All authors have contributed equally.

\section{CONFLICTS OF INTERESTS}

Declared none

\section{REFERENCES}

1. Tucker EL, Cao Y, Fox ER, Sweet BVJCP. The drug shortage era: a scoping review of the literature 2001-2019. Therapeutics 2020;108:1150-5.

2. Holcombe B, Mattox TW, Plogsted SJNiCP. Drug shortages: effect on parenteral nutrition therapy. Nutr Clin Pract 2018;33:53-61.

3. Ventola CLJP. The drug shortage crisis in the United States: causes, impact, and management strategies. Therapeutics 2011;36:740.

4. U. S. Food and Drug Administration. Drug shortages infographic; 2019. Available from: https://www.fda.gov/ drugs/drug-shortages/drug-shortages-infographic. [Last accessed on $20 \mathrm{Apr} 2021]$.

5. Fox ER, Birt A, James KB, Kokko H, Salverson S, Soflin DLJAjoh-sp. ASHP guidelines on managing drug product shortages in hospitals and health systems. Am J Health Syst Pharm 2009;66:1399-406.

6. Phuong JM, Penm J, Chaar B, Oldfield LD, Moles RJPo. The impacts of medication shortages on patient outcomes: a scoping review. PloS One 2019;14:e0215837.

7. McLaughlin M, Kotis D, Thomson K, Harrison M, Fennessy G, Postelnick M, et al. Effects on patient care caused by drug shortages: a survey. J Manag Care Pharm 2013;19:783-8.

8. Association AH. Recent trends in hospital drug spending and manufacturer shortages; 2019. Available from: https://www.aha.org/2019-01-15-recent-trends-hospital-drugspending-and-manufacturer-shortages. [Last accessed on $10 \mathrm{Feb}$ 2021]

9. Sacks CA, Kesselheim AS, Fralick MJJim. The shortage of normal saline in the wake of Hurricane Maria. JAMA Intern Med 2018;178:885-6.

10. Vail E, Gershengorn HB, Hua M, Walkey AJ, Rubenfeld G, Wunsch HJJ. Association between US norepinephrine shortage 
and mortality among patients with septic shock. JAMA 2017;317:1433-42.

11. Donohue JM, Angus DCJJ. National shortages of generic sterile injectable drugs: norepinephrine as a case study of potential harm. JAMA 2017;317:1415-7.

12. Sp M, PD, Mk H. A clinical study of siddha herbal preparation-m $\mathrm{v}$ kashayam for the treatment, control, and management of covid-19. Asian J Pharm Clin Res 2021;14:104-7.

13. Dewi YA, Permana AD, Oktrivianto DA. The impact of covid-19 pandemic to head and neck cancer care in hasan sadikin hospital bandung, Indonesia. Int J Pharm Pharm Sci 2021;13:63-6.

14. Badreldin HA, Atallah BJRiS, Pharmacy A. Global drug shortages due to COVID-19: impact on patient care and mitigation strategies. Res Social Adm Pharm 2021;17:1946-9.

15. BV, Babu A, Maria F, Antony S. the potential of remdesivir against sars cov 2: a review. Int J Curr Pharm Res 2020;12:20-3.

16. Viswanath K, Rn H, Basra SS, Chourey N. Coronavirus disease 2019 vaccination drive: the perceptions and acceptance of vaccination among health care workers. Asian J Pharm Clin Res 2021;14:177-81.

17. Abedrabboh K, Pilz M, Al-Fagih Z, Al-Fagih OS, Nebel JC, AlFagih L. Game theory to enhance stock management of personal protective equipment (PPE) during the COVID-19 outbreak. PLOS One 2021;16:e0246110.

18. Abedrabboh K, Pilz M, Al-Fagih Z, Al-Fagih OS, Nebel JC, AlFagih LJPO. Game theory to enhance stock management of personal protective equipment (PPE) during the COVID-19 outbreak. PLoS One 2021;16:e0246110.

19. Ranney ML, Griffeth V, Jha AK. Critical supply shortages-the need for ventilators and personal protective equipment during the covid-19 pandemic. New England J Med 2020;382:e41.

20. Barrera K, McNicoll CF, Sangji NFJBotACoS. Drug shortages: the invisible epidemic. Bulletin 2018;103:24-9.

21. European Association of Hospital Pharmacists (EAHP). Medicines shortage survey 2019; 2020. Available from: https://www.eahp.eu/practice-and-policy/medicinesshortages/2019-medicines-shortage-survey. [Last accessed on 10 Feb 2021]

22. National pharmaceutical pricing authority ministry of chemicals and fertilizers goi. Pharma Jan Samadhan; 2021. Available from: https://www.nppaindia.nic.in/en/homelinks/pharma-jansamadhan/. [Last accessed on 10 Feb 2021]

23. Hjacalyn M Duffin JP. Medicine shortages in light of COVID-19: a wake-up call for drug security. The Hill Times; 2020.
24. Drug shortages Canada. Summary Report: Bell Canada under contract with Health Canada; 2021. Available from: https://www.drugshortagescanada.ca/rws-search?perform=1. [Last accessed on 10 Feb 2021]

25. European Association of Hospital Pharmacists (EAHP). Medicines Shortage Survey; 2014. Available from: https://www.eahp.eu/practice-and-policy/medicinesshortages/2014-medicines-shortage-survey. [Last accessed on 10 Feb 2021]

26. U. S. Food and drug administration. About FDA; 2020. Available from: https://www.fda.gov/about-fda. [Last accessed on 10 Feb 2021]

27. European Association of Hospital Pharmacists (EAHP). Who we are; 2021. Available from: https://www.eahp.eu/aboutus/who-we-are. [Last accessed on 10 Feb 2021]

28. ISPE. Report on the ISPE drug shortages survey; 2013. Available from: https://ispe.org/sites/default/files/initiatives/drugshortages/2013-ISPE-drug-shortages-survey-report.pdf. [Last accessed on 10 Feb 2021]

29. U. S. Food and drug administration. Current and resolved drug shortages and discontinuations reported to FDA; 2021. Available from: https://www.accessdata.fda.gov/ scripts/drugshortages/. [Last accessed on 10 Feb 2021]

30. Medicines shortages in European Hospitals. Eur J Hospital Pharm; 2014. Available from: https://www.eahp.eu/ sites/default/files/files/shortages\%20report16_09.pdf. [Last accessed on 10 Feb 2021]

31. Miljkovic N, Gibbons N, Batista A, Fitzpatrick RW, Underhill J, Horak P. Results of EAHP's 2018 survey on medicines shortages. Eur J Hospital Pharm 2019;26:60.

32. Miller FA, Young SB, Dobrow M, Shojania KGJBQ, Safety. Vulnerability of the medical product supply chain: the wake-up call of COVID-19. BMJ 2021;30:331-5.

33. Food and Drug Administration DoHaHS. Report on Drug Shortages; 2017.

34. Gray A, Manasse Jr HR. Shortages of medicines: a complex global challenge. SciELO Public Health; 2012.

35. K Oanh Ha AR. Now the world's hospitals are running out of vital rubber gloves. Bloomberg; 2020.

36. Reed BN, Fox ER, Konig M, Jackevicius CA, Masoudi FA, Rabinstein AA, et al. The impact of drug shortages on patients with cardiovascular disease: causes, consequences, and a call to action. Am Heart J 2016;175:130-41. 